\title{
The Pedagogical Potential of Information and Communication Technologies in the Formation of Ethnic and Cultural Awareness of Younger Schoolchildren
}

\author{
Gubanihina Elena, Klyueva Elena, Kudakova Natalya, Naumova Tatyana, \\ Zhestkova Elena \\ Lobachevsky State University of Nizhny Novgorod (Arzamas branch). Address: K.Marx 36, Arzamas, 607220,
} Russia.

\begin{abstract}
Modern social and cultural environment of educational institutions are characterized by multi-ethnicity, as well as the ambiguous attitude of one social group to the members of different cultural and ethnic communities. Therefore, one of the most important tasks is the education of children in the spirit of peace and respect for all nations and peoples; formation of communicative skills and ability to interact with the representatives of different nations and religions. Achieving this goal is possible thanks to targeted multicultural education, which targets are defined by state strategy in the field of inter-ethnic harmony and harmonization of interethnic relations. The authors emphasize the formation of ethnic and cultural awareness of younger schoolchildren: reveal the essence and structure of ethnic awareness, the diagnostics results of the formation level of its components with the primary schoolchildren, consider the possibility of using information and communication technologies in the classroom and in extracurricular activities.

The article reveals the pedagogical potential use of Internet resources in the creation of presentations, movies, virtual tours, virtual museums, thematic projects, Web-based quests and virtual newspapers. The features of the individual and group work organization and joint work with teachers and parents are considered.
\end{abstract}

Keywords: ethno-cultural awareness, educational process, primary school pupil, information and communication technologies.

\section{INTRODUCTION}

A characteristic feature of our time is the coexistence of people in a multicultural society. The peculiarity of Russia is that it has a population of more than a hundred indigenous peoples living in different territories since ancient times. Based on this, the most important task of modern pedagogy becomes the formation of personality, which has ethnic and cultural awareness, ready for intercultural interaction and cooperation, respect for the representatives of different ethnic groups and their cultures $[11,13,14,15]$.

Content analysis of research on this issue leads to the conclusion that the concept of "ethno-cultural awareness" and "ethno-cultural competence" are not identical. Ethno-cultural competence is formed throughout life and manifests itself in skills and models of intercultural communication (TV Poshtareva, AB Afanasyev, VG Krys'ko) $[1,6,10]$. At primary school age formation of its substantial bases ethnic and cultural awareness is expedient (AR Georgyan, SV Mazharenko, SA Goncharov, LM. Kostin, IA Khomenko, LA Tkachenko) $[2,8,12]$.
According to the definition given by PY Sokolova, by ethno-cultural awareness of primary school pupils is understood "integrative personal education, which consists in the adoption and understanding by primary school pupils a certain set of ethno-cultural ideas, concepts and knowledge to reveal positive, emotional and value-tolerant and respectful, peculiar to this age, attitude to the representatives to various ethnic groups and their cultures in the process of intercultural interaction" $[11$, p. eleven].

The scientist believes that the formation of ethnic and cultural awareness of primary school pupils should be carried out consistently, step by step, including mastery of ethno-cultural ideas, concepts and knowledge.

One of the means of formation of ethnic awareness of children of primary school age are information and communication technologies have become an integral part of education and allowing the maximum to implement the principles of clarity, accessibility and age-appropriate. It should be noted that one of the priorities of the new educational standards is to focus on the active use of information http://dx.doi.org/ 10.17770/etr2017vol2.2580 
and communication technologies in education of younger schoolchildren. They involve the use of digital resources, online tools to access information and its usage to implement educational purposes.

The article focuses on the formation of ethnic and cultural awareness of primary school children in the course of acquaintance with the culture of the peoples living in the Nizhny Novgorod region.

\section{MATERIALS AND METHODS}

Having presented the theoretical foundations of the study, it is taken an attempt of the possibility to empirically substantiate pedagogical use of information and communication technologies in the formation of younger schoolchildren ethnic and cultural awareness comparing the results of diagnostic section of its components formation with the students in the control and experimental classes.

Defining the level of formation of ethnic and cultural awareness in young school-age children, we relied on the criteria: knowledge, existence and nature of interest, respectful and tolerant attitude towards representatives of various ethnic groups.

For each criterion qualitative characteristic of its establishment was given. Layered characteristic criteria are presented in Table 1.

Table 1

Levels of formation of ethno cultural criteria Primary school pupils awareness

\begin{tabular}{|c|c|}
\hline \multicolumn{2}{|r|}{ awareness } \\
\hline Criteria & Levels \\
\hline $\begin{array}{l}\text { 1) Knowledge of the } \\
\text { field of culture of the } \\
\text { peoples living on the } \\
\text { territory of Nizhny } \\
\text { Novgorod Region } \\
\text { (Russian, } \\
\text { Mordvinians, Tatars, } \\
\text { Chuvash) }\end{array}$ & $\begin{array}{l}\text { High level - availability and } \\
\text { possession of ethno -cultural } \\
\text { knowledge. } \\
\text { Middle level - partial ownership of } \\
\text { ethno-cultural knowledge. } \\
\text { Low level - lack of understanding and } \\
\text { a lack of ethnic and cultural } \\
\text { knowledge. }\end{array}$ \\
\hline $\begin{array}{l}\text { 2) The interest in the } \\
\text { knowledge of the } \\
\text { diversity of cultures } \\
\text { and the acquisition of } \\
\text { new information of } \\
\text { ethno-cultural } \\
\text { character. }\end{array}$ & $\begin{array}{l}\text { High level - there is a stable demand } \\
\text { for knowledge of ethno-cultural } \\
\text { diversity and positive motivation to } \\
\text { interact in a multicultural society. } \\
\text { Middle level - manifestation of } \\
\text { situational character in the knowledge } \\
\text { of ethnic and cultural diversity and } \\
\text { interaction with representatives of } \\
\text { other nations. } \\
\text { Low level - lack of willingness and } \\
\text { needs in knowledge and interaction } \\
\text { with representatives of other ethnic } \\
\text { groups. }\end{array}$ \\
\hline $\begin{array}{l}\text { 3) Respectful, tolerant } \\
\text { attitude towards } \\
\text { representatives of } \\
\text { various ethnic groups } \\
\text { and understanding of } \\
\text { common culture. }\end{array}$ & $\begin{array}{l}\text { High level - a manifestation of } \\
\text { positive emotional responses to } \\
\text { representatives of other ethnic groups } \\
\text { in real situations. } \\
\text { Middle level - fragile manifestations } \\
\text { of positive emotional responses to } \\
\text { representatives of other ethnic groups } \\
\text { in real situations. } \\
\text { Low level - lack of positive emotional } \\
\text { responses to representatives of other } \\
\text { ethnic groups in real situations. }\end{array}$ \\
\hline
\end{tabular}

To study the level of the criteria formation outlined above, the following methods were used: a questionnaire, which questions are based on questionnaires by EA Angarhaevoy, MB Kozhanova, SV Mazharenko, TV Poshtarevoy, PY Sokolova; monitoring, modification sociometry "Treat candy" (EK Suslova), the diagnostic task "Letter to a friend from other town" (based on diagnostic tasks by OV Dybina [4]).

\section{RESULTS AND DISCUSSION}

The empirical part of the study consisted of three phases. The aim of ascertaining stage of pedagogical experiment was to identify the level of formation of students' awareness of ethnic and cultural criteria at 3 "A" and 3 "B" classes. Experimental work took place on the basis of MBOU "School № 15", MBOU "School № 12" MBOU "School № 1" of Arzamas Nizhny Novgorod region. In the experiment, 138 students were involved. Control groups were set up for the implementation of the experimental purposes (CG), consisting of 69 students of class 3 "A", and the experimental group (EG), which also includes 69 pupils of 3 "B" class.

Diagnostics results of knowledge formation in the field of the peoples culture living in the Nizhny Novgorod region testify the low level for the majority of students (KG - 48 people, accounting for $69.6 \%$, EG - $45(65.2 \%))$. Minor group consisted of students with an average level of knowledge (CG - 12 (17.4\%), EG - 12 pupils (17.4\%)). High level of knowledge was demonstrated only by 9 respondents CG $-13 \%$, and 12 people EG, which accounted for $17.4 \%$ (see Figure 1.).

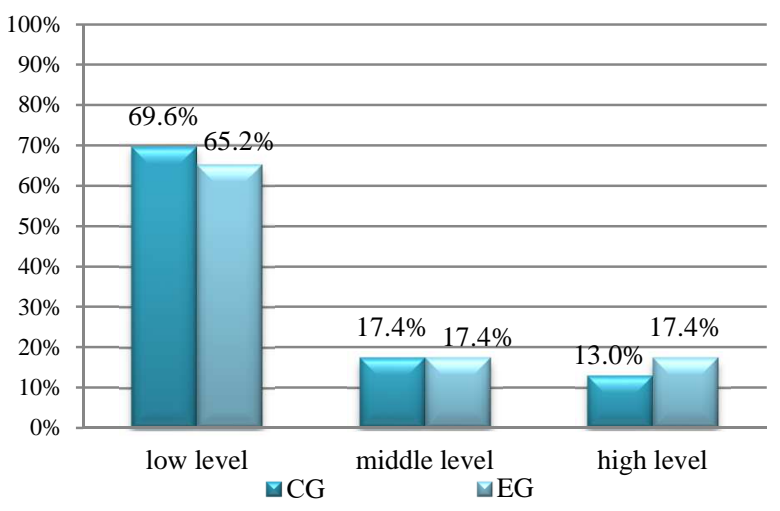

Figure 1. Maturity of knowledge from the field of the peoples culture living on the territory of Nizhny Novgorod region in the beginning of the experiment

In the context of the study of the presence of interest in the knowledge of cultures and the acquisition of new information diversity of ethnocultural nature was detected motivation to acquire new knowledge and cross-cultural communication and interaction. Availability of motivation reveals the answers to the questionnaire.

The analysis results of the responses testify to the interest of all students (100\%) in both groups in the study of folklore, crafts, celebrations of the peoples living on the territory of the Nizhny Novgorod 
region. $30.4 \%$ of respondents $\mathrm{CG}$ (21 pupils) and $34.8 \%$ of EG (24 pupils) believe that to understand each other to the representatives of different nations help familiarity with their culture, folklore and traditions.

Analysis of students' responses to the survey questions (Do you want to learn the culture of their own and other peoples? Do you want to travel to another country?) revealed that a stable demand for knowledge of ethno-cultural diversity and positive motivation to interact in a multicultural society is characteristic of the $60 \mathrm{CG}(87 \%)$ and 61 pupils EG $(91.3 \%)$. Lack of desire and the need for knowledge and interaction with representatives of other ethnic groups were found in CG 9 pupils (13\%) and EG 6 children $(8.7 \%)$.

Determine the nature of the interest to know the ethnic and cultural diversity and positive motivation to interact in a multicultural society also contributed to the diagnostic task, "Letter to a friend from out of town." The interest in the knowledge of the diversity of cultures and the acquisition of new information, ethno-cultural character was found in almost half of the respondents (54 people CG - 78.3\% and 48 EG $69.6 \%$ ), the rest of the students (15 persons CG$21.7 \%$ and 21 EG pupils - 30.4\%) did not wish to write a letter, chat with a peer from another city. This situation made it possible to identify the students who agreed to interact with other people and children who have refused cooperation. Summary of results of the survey and the methodology presented evidence of the presence of children with situational interest in the knowledge of ethnic and cultural diversity and interaction with representatives of other nations. For these groups of learners is characterized by an average level of interest in the knowledge of the diversity of cultures and the acquisition of new information of ethno-cultural nature ( 9 pupils CG $13 \%$ and 15 pupils EG - 21.7\%).

The results identifying the level of interest in the formation of knowledge of the cultures diversity and the acquisition of new information of ethnic and cultural character are shown in Figure 2.

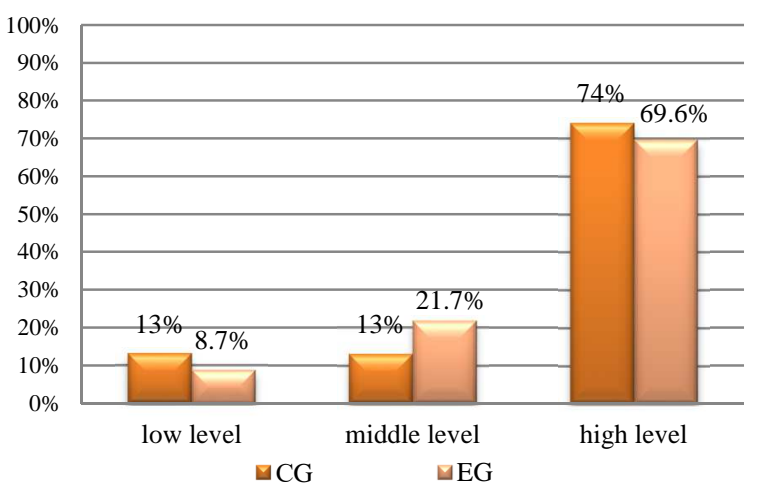

Figure 2. Levels of formation of interest to the knowledge of the cultures diversity and the acquisition of new information of ethnocultural nature at the beginning of the experiment
The level of development of a respectful, tolerant attitude towards representatives of various ethnic groups and understanding of common groups was estimated on the basis of questionnaires and methodology "Treat candy."

Analysis of the resulting survey data showed that more than half of primary school respondents refer with pride and love to their native land (54 CG children $-78.3 \%$, and the EG 60 children - 87\%) and Russia (60 CG-87 children \%, 63 students from the EG -91.3\%). Note that among the respondents no one responded negatively and adversely about his native land and Russia.

The survey results allow to state that the majority of respondents (48 people CG - 69.6\%, 54 persons EG $-78.3 \%$ ) believes that people of different nationalities are to live in peace, as the friendship between the peoples can help to bring peace on earth. The rest of the students (9 pupils CG - 13\% and 15 pupils EG - 21.7\%) believe that friendship between ethnic groups does not always help to bring peace on earth.

Most students expressed a desire to make friends with children of Tatar, Mordovia and Chuvashia nationalities (51 CG of respondents $-73.9 \%$, and the EG $60-87 \%)$. However, some children did not choose as friends of other ethnic groups (18 CG of respondents - 26.1\%, and EG 9 people - 13\%), explained by the fact that they are not ready to communicate with the representatives of those nations, of which they know nothing.

Further, the diagnostic work, in order to identify the nature of the relationship to the children of other nationalities, we had a method of "Treat candy." Each child was asked to choose the person with whom he shared his candy. Children had to choose pictures that depicted children of Tatar, Chuvashian, Mordovian and Russian nationalities. Pupils were announced the names and nationality shown peers. Most children were happy to have completed the task, sharing sweets, and regardless of gender and nationality. Sweets were distributed to everyone equally. Usually, the students began handing out candy to those illustrations that were closest to them. Thus, we can say that the ethnicity of children depicted in the illustrations was not important for most of the children in the distribution of sweets.

Some children behaved selfishly, leaving most or all of the candy themselves. They gave preference to one ethnic group and refused to share the candy with the children of other nationalities.

Summarizing the results, we can conclude:

- 54 pupils CG and EG - 60, that is $78.3 \%$ and $87 \%$ of children, respectively, are friendly in their actions to all children in the illustrations, so depicted nationality of the child is not important for them; 
- 9 pupils CG and EG 3 pupil, which is $13 \%$ and $4.3 \%$, respectively, selfish, self-centered on their desires;

- 6 pupils CG and EG 6 pupils, this is $8.6 \%$ of the children treated only some of the children of certain nations.

So, in the ascertaining stage of the experiment a low level of formation of respectful, tolerant attitude towards representatives of different ethnic groups and understanding of common cultural is characterized by $13 \%$ and $4.3 \%$ of respondents in control and experimental groups (respectively - 9 children and 3 child CG EG), average-to $8.6 \%$ of respondents in each group (for 6 children), high - for $78,3 \%$ and $87 \%$ of respondents in control and experimental groups (respectively - 54 children and 60 CG EG children).

The results of the study of development respectful, tolerant attitude towards representatives of various ethnic groups and students' understanding of common sense are shown in Figure 3.

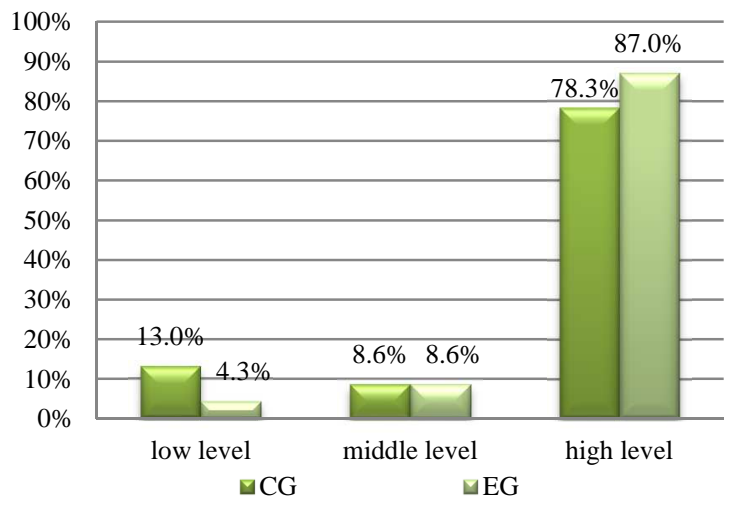

Figure 3. Level of development of respectful, tolerant attitude towards representatives of various ethnic groups at the beginning of the experiment

Carrying out of diagnostics has allowed to receive overview of the development level of the main components of ethnic and cultural awareness of primary school children. It should be noted that most of the younger students have an interest in the study of other cultures, in interaction with the representatives of other nationalities. However, further work is needed to build knowledge and develop a respectful, tolerant attitude towards representatives of various ethnic groups.

During the second phase of the experimental work the introduction of experimental class students to the culture of the peoples living in the Nizhny Novgorod region was carried out [3]. Formation of ethno cultural representations started with such means as: folk tales, folk toys, ornaments, dance, etc. Boosting children's interest helped work with the multimedia project "Russian Museum: Virtual Branch" that enabled visually introduce children to the history of Russian fine art and art of other peoples, their history and culture.
Children have been held a virtual tour on the theme "A friendly family of nations", "Nizhny Novgorod Region World peoples crafts", "The Magic of the national ornament" and others. Web quests have been proposed to consolidate the knowledge to students, in which they had to reproduce the knowledge about the elements ornaments Russian costumes, Mordovian, Tatar, Chuvash peoples, to make the national costume of the different elements to determine the nationality of the passage of a literary work (the fairy tale "The wolf and the goat" (Russian) "Eight leg's dog" (Mordovia), "Shah - cock" (Tatar ) "," The Fox and the Woodpecker "(Chuvash)), household items. This educational tool was used in all phases of lessons and educational activities, as well as for the organization of independent work of students. It is important to note the role of the family. As part of the job quest require collaboration of the child and his parents, adults were indirectly involved in the educational process $[5,9]$.

During the lessons on the subject "The world around us" students performed a presentation of group projects "Russian (Mordovian, Tatar, Chuvash, etc.) the nation in the family of peoples of Russia". According to the results of the project groups of students a virtual newspaper was created, the content of which reflects the cultural elements of the peoples living in the Nizhny Novgorod region. The results of the children's work was reflected on the website of the educational project "Letopisi.ru".

To generalize and systematize the knowledge gained has allowed the children to work with electronic resources Dipity service - Ribbon time at which significant events in the history of the peoples are reflected in chronological order [7].

In the final stage we repeated diagnostics which was conducted using research methods presented earlier.

The chart below reflects the results of reformation of the diagnostic cut-off levels of the above components of elementary school pupils of ethnic awareness.

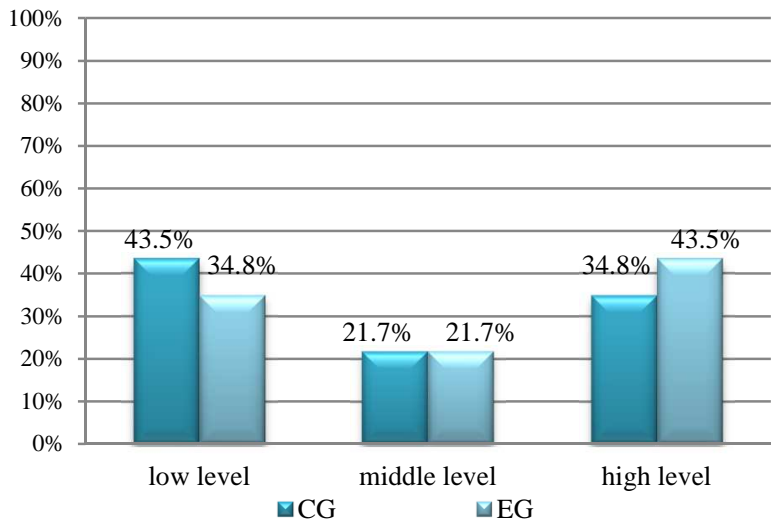

Figure 4. Maturity of knowledge from the field of culture of the peoples living in the Nizhny Novgorod region at the end of the experiment 


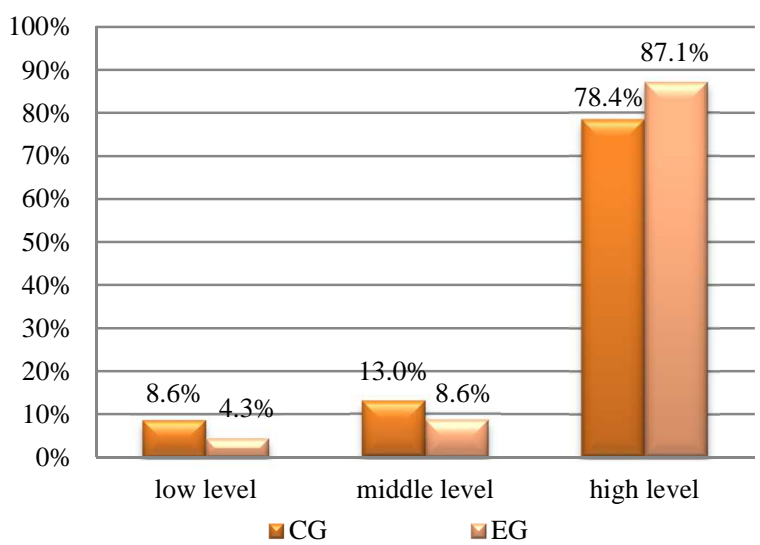

Figure 5. Levels of formation of interest to know the diversity of cultures and the acquisition of new information, ethno-cultural nature at the end of the experiment

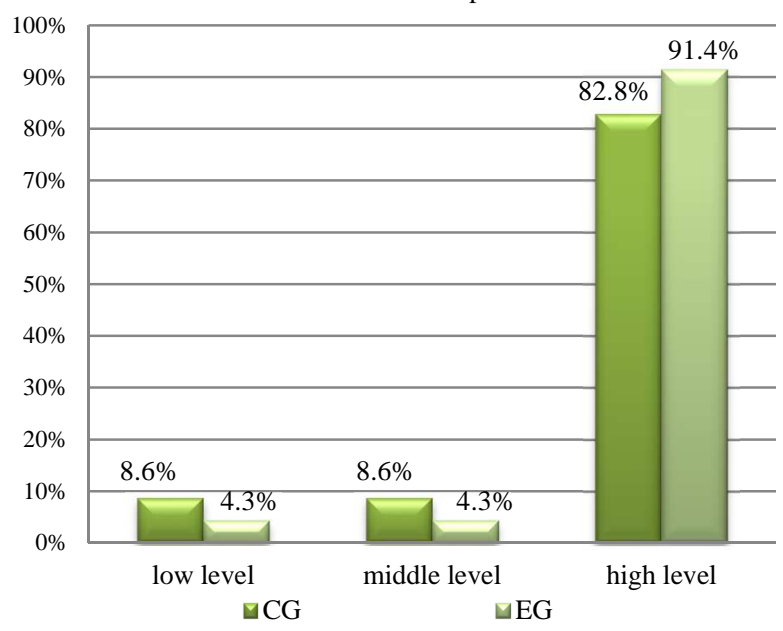

Figure 6. The level of development of a respectful, tolerant attitude towards representatives of various ethnic groups at the end of the experiment

\section{CONCLUSION}

Thus, on the basis of the data presented, we can conclude that the positive dynamics in the formation of students' awareness of ethnic and cultural components, which demonstrates the effectiveness of the work was carried out with the use of information and communication technologies for the implementation of various educational and educational problems.

During pedagogical experiment observed the experimental class students were interested in the study of culture as their own and other cultures, understanding of the unity and uniqueness of cultures, the desire of many students to communicate with representatives of other nationalities and positive emotional value to display it.

\section{REFERENCES}

[1] Afanasiev A.B. Ethno cultural education: essence, content, structure, problems of improving / $\mathrm{AB}$ Afanasiev // Knowledge. Understanding. Ability, 2009, № 3, pp 189-195.

[2] Georgyan A.R. Formation of civil identity of preschool children on the basis of ethnic and cultural awareness [electronic resource] / AR Georgyan. Access: http://www.rusnauka.com

[3] Gubanihina E.V. Preservation and development of national cultural traditions (in local history material) as a basis for the formation of moral and patriotic qualities of preschool children / VR Nikonov, E. Gubanihina // A regional approach to multicultural education of children and young people: Proceedings of All-Russian scientific-practical conference in the framework of the V Open Regional Scientific and Methodological Symposium "Our world - the world of childhood," April 21, 2016 / under total. Ed. EV Klyuev, TV Naumova; Arzamas branch UNN, IHOiK RAO educational department. Arzamas, Manage. form. adm. Arzamas district, Arzamas: Arzamas branch UNN, 2016, pp 159-166.

[4] Diagnosis of child focus on the world of the family: Training handbook. - M.: Pedagogical Education Center, 2009. - 77 p.

[5] Klyueva E.V. Preparing students for the formation of inter-ethnic harmony in schoolchildren / EV. Klyuyeva // Elementary School, 2014, №9, pp 65-70.

[6] Krys'ko V.G. Ethno psychological Dictionary / VG Krys'ko. - M .: SAG, 1999, 343 p.

[7] Kudakova N.S. Formation of ICT competence in the conditions of the implementation of the GEF / N.S. Kudakova // State educational standards: the problem of continuity and implementation: Materials of AllRussian scientific-practical conference / Ed. Ed. Zhestkova EA, Arzamas: Arzamas branch UNN, 2015, pp 443-447.

[8] Mazharenko S.V. Formation of ethno cultural awareness of children in preschool educational institution: dis. ... Cand. ped. Sciences: 13.00.01 / Mazharenko Svetlana Viktorovna. - Vladikavkaz, 2009. - $231 \mathrm{p}$.

[9] Naumova T.V. Problems and effective practice of pedagogical interaction of parents and teachers in multicultural education preschoolers /T.V. Naumova // A regional approach to multicultural education of children and young people: Proceedings of AllRussian scientific-practical conference in the framework of the V Open Regional Scientific and Methodological Symposium "Our world - the world of childhood," April 21, 2016 / under total. Ed. EV Klyuev, TV Naumova; Arzamas branch UNN, IHOiK RAO educational department.. Arzamas, Manage. form. adm. Arzamas district, Arzamas: Arzamas branch UNN, 2016, pp 52-63.

[10] Poshtareva T. Formation of ethno cultural competence / TV Poshtareva // Pedagogy, 2005, № 3, pp 35-42.

[11] Sokolov PY Formation of ethno cultural knowledge of primary school students in a secondary school: Dis. ... Cand. ped. Sciences: 13.00.01 / Sokolova Y. Pelagia. - Saransk, 2014. - 189 p.

[12] Tkachenko LA System of preschool on formation of ethno cultural competence of children [electronic resource] / LA Tkachenko. - Access: http://imkbor.ucoz.ru/Docks/opitrabot/tkachenko.doc

[13] The federal target program "Strengthening the unity of the Russian nation and ethno-cultural development of the peoples of Russia (2014-2020)" [Electronic resource]. - Access: http://www.rg.ru/ 
[14] The federal state educational standard of primary education [electronic resource]. - Access: http://nachalka.edu.ru/catalog.asp?ob_no=15648

[15] Zhestkova E. Specifics of educational activity antimotivation in future teachers subject to the training period / Assel Bakirovna Akpayeva, Natalia Valentinovna Ivanova, Tatiana Ivanovna Luchina, Elena Viktorovna Minaeva, Elena Alexandrovna Zhestkova // International Review of Management and Marketing. - 2016. - №3. - p.265-259. 